\title{
Experiment Teaching Reform of "Software Technology Foundation" based on VB6.0
}

\author{
XiangMin Lun, Hong Men and Yimin Hou* \\ School of Automation Engineering, Northeast Dianli University, Jilin, Jilin 132012 \\ ymh7821@163.com
}

Keywords: Software Technology Foundation; Experimental Teaching System; Teaching Reform; VB6.0

\begin{abstract}
Software Technology Foundation" is an important basic course of automation major in the proposed university. In order to solve the main problems in experimental teaching of the course, this paper studies how to design a set of experimental teaching software for "Software Technology Foundation" under the platform of VB6.0 software development in combination with professional features, and makes full use of existing hardware and software foundation conditions. The development is based on the basic experimental data structure of the $\mathrm{C}$ language, data processing module and comprehensive experimental and other parts. Combined with the actual situation of the students, the corresponding teaching reform and exploration have been carried out, which has achieved good teaching results in the practical application.
\end{abstract}

\section{Introduction}

With the rapid development and popularity of computer technology, basic computer teaching for non-computer professional students has been generally strengthened[1]. "Software Technology Foundation" is a compulsory course of automation professionals in the proposed school, and students are required to master the basic knowledge of data structures, basic technology of program design and the processes of software development to train practical ability of program design and development[2], therefore, it is necessary to pay attention to the experimental part of the course. In terms of the existing problems in the experimental teaching of the "Software Technology Foundation", the corresponding teaching reform and exploration have been conducted in combination with the actual situation of the students. It is necessary to design a set of experimental teaching software for "Software Technology Foundation" under the platform of VB6.0 software development. The development is based on the basic experimental data structure of the $\mathrm{C}$ language, data processing module and comprehensive experimental and other parts. Better teaching results have been achieved in the practical application, while improving teaching methods and conducting the reform for experimental teaching.

\section{Main Problems of Experimental Teaching}

With the development of science and technology and higher requirements of the experimental teaching performance, the main problems faced by experimental teaching of this course include the following two points.

1) Since the experimental teaching of the course has no major changes over the years, conventional teaching methods cannot effectively present experimental data structures and the abstraction and instantaneous dynamic characteristics of algorithms, and operation and analysis process of algorithms. It is difficult for students to master $\mathrm{C}$ language and apply, and they are also quite difficult to have a good understanding of the abstract and boring concepts and the invisible incomprehensible algorithm [3].

2) Since the online time is not enough for students, students only focus on the verification experiment listed in the program guide books, and they fail to grasp programming methods and programming techniques because 
of the lack of adequate programming and commissioning practice, making it impossible to appreciate the importance and usefulness of the course.

These problems affect each other and restrict mutually, causing to reduce the effect of Experimental Teaching of the course.

\section{Experimental Teaching Software Design}

To solve these problems, researchers should design and develop the experimental teaching software under the environment of VB6.0 software development platform in combination with the actual situation of the students and on the basis of the theoretical knowledge, which should be conducted according to the guiding ideology of "paying attention to theory and strengthening the application"[4]. There are two kinds of system login, including the system login for teachers and that for students, teachers can conduct such experimental teaching activities as explanation and demonstration of a pilot project knowledge points, debugging and analysis for operating results and algorithm and so on; and students can conduct such experimental activities as coding, debugging and observation for a particular experiment project and analysis for experimental results of experimental activities.

Experimental teaching contains the basic structure of the experimental data, experimental data processing module and integrated experiment[5-8]. The basic experimental data structure module includes verification experiments for such data structures as linear tables, stacks, queues, trees, figures and so on. The experiment module can display algorithm description, algorithm diagrams and algorithm code of the selected experiments. In terms of some key unit, it is necessary for teachers to explain while conducting demonstration to ensure the intuitive and vivid teaching effect, which helps to understand the course and improve the boring teaching methods, and the quality of teaching will be improved significantly. Teachers can also operate experiment list and remove the unnecessary the experiment items or add a new pilot project. In addition, teachers can also apply background software WIN-TC.exe to debug the program in order to achieve dynamic visualization for program operation step by step. Students can observe operating results through commissioning of the program to summarize and analyze the advantages and disadvantages of algorithm, which can stimulate students' enthusiasm for learning and improve learning outcomes[2].

Improving data processing module mainly involves such two algorithms as sorting and searching. Sorting is the ranking of inserting, selecting, exchanging and merging; searching mainly includes the order of linear form, binary and searching in block as well as searching of binary sort tree. The system should be able to conduct the dynamic presentation for the computing process of such relevant algorithms as searching and sorting and can debug the program and analyze the results through applying the source background source program coded through $C$ language.

Comprehensive experiment consists of such three parts as topic selecting, design and submission, the students can view the experiment purpose and requirements through topic selecting and can conduct program structure design and carry out $\mathrm{C}$ language programming, compiling, debugging and running by calling Win-tc program, and then enter the test reporting templates through link, and related content of the experiments such as title, prep requirements, experimental purposes and the experiment content have been automatically added to the report. Students need to fill debugged code into the appropriate position and then screenshot the experimental results to store in the document, and then fill in class, student number, name and other basic information, the test report can be submitted after the careful check. The segment focuses on tapping the student potential, broadening their horizons and developing students' creative thinking, so that students can change from passive response to experiment to active research for experiments. So that students' coding ability and comprehensive application ability can be improved to a great extent. 


\section{Effects of Experimental Teaching}

The experimental teaching system has been used in 2011, 2012 automation majors, the experimental course has made breakthrough progress in the following areas after two-year reform and practice:

1) The student attendance rate of experiment class ahs been significantly improved, specific statistics has shown that the attendance rate has been improved from $93 \%$ in 2010 to $99 \%$ in 2011.

2) Student interest in learning has been significantly increased, through exchanges and feedback with students, most of the students believe that new experimental teaching model not only can improve the ability of high-level language programming in the limited classroom time, but also can acquire the relevant algorithm design method and get development experience at the end of the course, so that students can "apply what they has learned to practice."

3) The project has not only pointed out the experimental requirements, objectives, content and reporting requirements, but also has a mastery of related theoretical knowledge, which is more conducive for students to have better digestion and absorption of knowledge, in addition, students can stimulate their independent thinking and interest and initiative for exploration, to develop the rigorous style of meticulous design, careful observation, careful analysis and scientific summary.

4) Experimental teaching and management methods should be gradually updated in order to provide students with a broader time and space. In terms of specific methods, teachers should put forward questions, laboratory should provide conditions, the students should design independently and check the experimental results jointly, and the method of asking questions in the classroom, analyzing problems after class and solving problems through experiments should be applied to provide students with the environment for analyzing and solving problems independently and create an engineering way of thinking on the basis of verifying theories and explaining problems through experiments.

5) The students' practical abilities have been improved significantly, students can have a mastery of $\mathrm{C}$ language programming and programming techniques after experiencing the learning and practicing the data structure experiment of $\mathrm{C}$ language, data processing experiment and comprehensive experiment, so that the students' practical abilities have been cultivated in limited curricular time to a great extent. It is noted that the number of students participating in extracurricular scientific and technological activities increased significantly, and they achieve better results.

\section{Conclusions}

In short, the experimental teaching system for "Software Technology Foundation" has improved boring teaching methods, and the teaching effect is intuitive and vivid. Students can improve the programming skills and develop good programming habits through repeated experiencing, summarizing and analyzing the advantages and disadvantages of various algorithms. The system also can provide students with the opportunities to conduct extracurricular comprehensive application-oriented laboratory exercises, focusing on tapping the potential of students, cultivating students 'innovative thinking, so that students can change from passive response to experiments to active research for experiments, which can improve Students' ability of the comprehensive application.

The project will not only stimulate students' enthusiasm, improve the quality of teaching, train student ability, but also achieve the reform for the teaching methods and content and constantly push forward the progress of new experimental teaching mode and means. 


\section{References}

[1] Di-Yi Chen, Xiao-Yi Ma, Quan-Cai Xin et al. Course Teaching Method Analysis for "Computer Software Technology Foundation”. Computer Education. 2009, (22):68-69.

[2] Shui-Li Zhang, Jun-Tang Dong, Yan-Hu Fan et al. Analysis and Practice for the Teaching Mode of “Software Technology Foundation". Journal of Yan'an University (Natural Science Edition) 2010,29 (2):56-59.

[3] Liu Yue, Huai-Yi Chen. Study for Course Teaching Reform for "Computer Soffware Technology Foundation". Journal of Jilin University, 2005, 23 (S0):145-148

[4] Xiang-Min Lun, Men Hong, Xiu-Yu, Zhang, Study and Design for the "Experimental Teaching System of Software Technology Foundation", China Education Innovation Herald, 2013, (32):33

[5] Guo-Li Song, Gong-Qi Gai, Dong-Mei Su. Research and Practice of the Open Expermi ental Teaching Mode. Research and Explorarion in Laboratory. 2010, 29(2):91-94.

[6] Ren-Jie Hu. To Create the Open Teaching Environment in Lab and Develop the Open and Self-Experimental Teaching. Research and Explorarion in Laboratory. 2010, 25(7):822-826.

[7] Ke-Lu, Xiao-Dong Zhang, Lijun Sun. Exploration on practical teaching of Software Technology Foundation. Experimental Technology and Management. 20013, 30 (4):169-171.

[8] Xiu-Qing Guo. Research on Cases-driven Teaching Method for Software Technology Foundation. Journal of EEE, 2006, 28(5): 23-26. 